\title{
Nilotinib first-line therapy in patients with Philadelphia chromosome-negative/BCR-ABL-positive chronic myeloid leukemia in chronic phase: ENEST1st sub-analysis
}

\author{
Andreas Hochhaus $^{1} \cdot$ François-Xavier Mahon ${ }^{2} \cdot$ Philipp le Coutre $^{3} \cdot$ Ljubomir Petrov $^{4} \cdot$ Jeroen J. W. M. Janssen $^{5}$. \\ Nicholas C. P. Cross ${ }^{6}$ - Delphine Rea ${ }^{7}$ - Fausto Castagnetti ${ }^{8} \cdot$ Andrzej Hellmann $^{9} \cdot$ Gianantonio Rosti $^{8}$. \\ Norbert Gattermann $^{10}$ • Maria Liz Paciello Coronel ${ }^{11}$ • Maria Asuncion Echeveste Gutierrez ${ }^{12}$. \\ Valentin Garcia-Gutierrez $^{11}$ • Beatrice Vincenzi ${ }^{13}$ - Luca Dezzani ${ }^{13}$ - Francis J. Giles ${ }^{14}$
}

Received: 25 January 2017 / Accepted: 27 January 2017 / Published online: 21 February 2017

(C) The Author(s) 2017. This article is published with open access at Springerlink.com

\begin{abstract}
Purpose The ENEST1st sub-analysis presents data based on Philadelphia chromosome (Ph) status, i.e., $\mathrm{Ph}+$ and $\mathrm{Ph}-/ B C R-A B L 1+$ chronic myeloid leukemia.

Methods Patients received nilotinib $300 \mathrm{mg}$ twice daily, up to 24 months.

Results At screening, 983 patients were identified as $\mathrm{Ph}+$ and 30 patients as $\mathrm{Ph}-/ B C R-A B L+$ based on cytogenetic and RT-PCR assessment; 76 patients had unknown karyotype (excluded from this sub-analysis). In the $\mathrm{Ph}-/ B C R$ $A B L 1+$ subgroup, no additional chromosomal aberrations were reported. In the $\mathrm{Ph}+$ subgroup, 952 patients had safety and molecular assessments. In the $\mathrm{Ph}-/ B C R$ $A B L 1+$ subgroup, 30 patients had safety assessments and
\end{abstract}

Andreas Hochhaus

andreas.hochhaus@med.uni-jena.de

1 Abteilung Hämatologie/Onkologie, Klinik für Innere Medizin II, Universitätsklinikum Jena, Am Klinikum 1, 07740 Jena, Germany

2 Laboratoire Hématopoïèse Leucémique et Cible Thérapeutique, Université Victor Ségalen, Bordeaux, France

3 Charité-Universitätsmedizin Berlin Campus Virchow, Berlin, Germany

4 Ion Chiricuta Institute of Oncology, Cluj-Napoca, Romania

5 Department of Hematology, VU University Medical Center, Amsterdam, The Netherlands

6 Faculty of Medicine, University of Southampton, Southampton, UK

7 Adult Hematology Department, Hôpital Saint-Louis, APHP, Paris, France

8 Department of Experimental, Diagnostic and Specialty Medicine, Institute of Hematology "L. \& A. Seràgnoli", "S Orsola-Malpighi" University Hospital, University of Bologna, Bologna, Italy
28 were followed up for molecular assessments. At 18 months, the molecular response (MR) 4 rate $\left[\mathrm{MR}^{4}\right.$; BCRABL1 $\leq 0.01 \%$ on International Scale (IS)] was similar in the $\mathrm{Ph}-/ B C R-A B L 1+(39.3 \%)$ and $\mathrm{Ph}+$ subgroups $(38.1 \%)$. By 24 months, the cumulative rates of major molecular response (BCR-ABL1 ${ }^{\mathrm{IS}} \leq 0.1 \%$;), $\mathrm{MR}^{4}$, and $\mathrm{MR}^{4.5}$ (BCR$\mathrm{ABL}^{\mathrm{IS}} \leq 0.0032 \%$ ) were $85.7,60.7$, and $50.0 \%$, respectively, in the $\mathrm{Ph}-/ B C R-A B L 1+$ subgroup, and 80.3, 54.7, and $38.3 \%$, respectively, in the $\mathrm{Ph}+$ subgroup. In both $\mathrm{Ph}-/ B C R-A B L 1+$ and $\mathrm{Ph}+$ subgroups, rash (20 and $22 \%$ ), pruritus (16.7 and 16.7\%), nasopharyngitis (13.3 and $10.4 \%$ ), fatigue (10 and $14.2 \%$ ), headache (10 and $15.8 \%$ ), and nausea (6.7 vs $11.4 \%$ ) were frequent non-hematologic adverse events, whereas hypophosphatemia (23.3 and

9 Department of Hematology, Medical University of Gdańsk, Gdańsk, Poland

10 Department of Hematology, Oncology, and Clinical Immunology, Universitätsklinikum Düsseldorf, Düsseldorf, Germany

11 Servicio de Hematología y Hemoterapia, IRYCIS, Hospital Universitario Ramón y Cajal, Madrid, Spain

12 Hospital de Donostia, San Sebastian, Spain

13 Novartis Oncology Region Europe, Origgio, Italy

14 Division of Hematology Oncology, Developmental Therapeutics Program, Northwestern University Feinberg School of Medicine, Chicago, IL, USA 
$6.8 \%$ ), anemia (10 and 6.5\%), and thrombocytopenia (3.3 and $10.2 \%$ ) were the common hematologic/biochemical laboratory events.

Conclusion Based on similar molecular response and safety results in both subgroups, we conclude that $\mathrm{Ph}-/ B C R-A B L 1+$ patients benefit from nilotinib in the same way as $\mathrm{Ph}+$ patients.

Keywords ENEST1st - Nilotinib - Chronic myeloid leukemia $\cdot$ Philadelphia chromosome negative/BCR-ABL positive

\section{Introduction}

Chronic myeloid leukemia (CML) is characterized by the presence of Philadelphia $(\mathrm{Ph})$ chromosome in $>95 \%$ of the cases. The $\mathrm{Ph}$ chromosome, formed as a result of a reciprocal translocation between chromosomes 9 and 22, carries a region that expresses the chimeric $B C R-A B L 1$ gene which encodes for the BCR-ABL1 fusion protein (Bartram et al. 1983; de Klein et al. 1982; Rowley 1973; Shtivelman et al. 1987)

In very few patients $(\sim 5 \%)$ with $\mathrm{CML}$, the $\mathrm{Ph}$ chromosome is not detectable despite $B C R-A B L 1$ positivity by fluorescent in situ hybridization or reverse transcriptase polymerase chain reaction (RT-PCR). The explanation for these cases are that there is a double recombination event involving chromosomes 9 and 22, and in some cases one or more other chromosomes (Bartram 1985; Fitzgerald and Morris 1991; Heim et al. 1985; La Starza et al. 2002; Nishigaki et al. 1992; Seong et al. 1999; Sessarego et al. 2000; Todoric-Zivanovic et al. 2006). Usually, patients with $\mathrm{Ph}-$ negative $(\mathrm{Ph}-) / B C R-A B L 1$-positive $(B C R-A B L 1+) \mathrm{CML}$ are clinically not distinguishable from patients with $\mathrm{Ph}+$ CML (Baccarani et al. 2013; Martiat et al. 1991; Seong et al. 1999).

Nilotinib, a second-generation BCR-ABL tyrosine kinase inhibitor (TKI) is approved for the treatment of adult patients with newly diagnosed $\mathrm{Ph}+\mathrm{CML}$ in chronic phase (CP) (Tasigna 2015). In the pivotal phase 3 ENESTnd trial in patients with newly diagnosed CML, nilotinib $300 \mathrm{mg}$ twice daily demonstrated efficacy, with patients achieving early and deep molecular responses and consistent longterm safety profile (Hochhaus et al. 2016b; Kantarjian et al. 2011; Larson et al. 2012; Saglio et al. 2010). Nilotinib or other TKIs have not been systematically investigated in patients with $\mathrm{Ph}-/ B C R-A B L 1+\mathrm{CML}$.

The ENEST1st study evaluated the safety and efficacy of nilotinib $300 \mathrm{mg}$ twice daily in a large population of patients with newly diagnosed $\mathrm{Ph}+$ or $\mathrm{Ph}-/ B C R$ $A B L 1+$ CML-CP. In the overall population, the primary endpoint of molecular response (MR) 4 [MR ${ }^{4}$; BCR-ABL1 $\leq 0.01 \%$ on the International Scale (IS)] at 18 months was achieved by $38.4 \%$ of patients (Hochhaus et al. 2016a). Here, we present data from a sub-analysis of the ENEST1st study based on the $\mathrm{Ph}$ status, i.e., $\mathrm{Ph}+\mathrm{CML}$ and $\mathrm{Ph}-/ B C R-A B L 1+\mathrm{CML}$.

\section{Patients and methods}

\section{Study design, patients and dosing}

The European phase 3b, multicenter, single-arm, open-label ENEST1st trial enrolled adult patients (aged $\geq 18$ years) with newly diagnosed ( $\leq 6$ months) $\mathrm{Ph}+$ or $\mathrm{Ph}-/ B C R$ $A B L 1+\mathrm{CML}-\mathrm{CP}$, with molecular confirmation of the $B C R$ $A B L$ fusion. Patients were required to have World Health Organization performance status $\leq 2$. Detailed eligibility criteria were previously reported (Hochhaus et al. 2016a). Patients were treated with nilotinib $300 \mathrm{mg}$ twice daily, and followed for up to 24 months. Dose escalation was not permitted, whereas dose interruptions were recommended in patients who experienced study drug-related, clinically significant nonhematologic or noncardiac adverse events (AEs) of grade $2 / 3$ severity, or study drug-related white blood cell- or platelet-related events of grade 3/4 severity.

The primary endpoint of the study was the rate of $\mathrm{MR}^{4}$ at 18 months. The secondary endpoints included the rates of major molecular response (MMR; BCR-ABL1 ${ }^{\mathrm{IS}} \leq 0.1 \%$ ), $\mathrm{MR}^{4}$, and $\mathrm{MR}^{4.5}\left(\mathrm{BCR}-\mathrm{ABL} 1{ }^{\mathrm{IS}} \leq 0.0032 \%\right)$ at and by 12 and 24 months of treatment, and safety. This subanalysis presents data based on the $\mathrm{Ph}$ status at diagnosis (Hochhaus et al. 2016a).

\section{Assessments and definitions}

Bone marrow cytogenetic assessments were performed within 8 weeks before the first dose of nilotinib. Cytogenetic assessments were performed and analyzed locally using standard methods on at least 20 metaphases; fluorescence in situ hybridization analyses were not used for response assessment. Patients with $\mathrm{Ph}-/ B C R-A B L 1+\mathrm{CML}$ and those with unconfirmed $\mathrm{Ph}$ status at screening and no $\mathrm{Ph}+$ metaphases at later time points were not assessed for cytogenetic responses.

At baseline, the $B C R-A B L 1$ transcript type was determined by multiplex polymerase chain reaction (PCR) (Cross et al. 1994) and DNA sequencing. In subsequent samples, $B C R-A B L 1$ transcripts were quantified every 3 months by quantitative real-time reverse transcriptase qRT-PCR testing of peripheral blood. Samples were analyzed at the designated European Treatment and Outcome Study (EUTOS) reference laboratories. For each sample, the ratio of $B C R-A B L 1$ transcripts vs control gene $(A B L)$ 
transcripts converted to IS was calculated (Hughes and Branford 2006; Müller et al. 2008).

Molecular response was defined according to the definitions of EUTOS (Cross et al. 2012).

National Cancer Institute Common Terminology Criteria for Adverse Events version 4.0 was used for toxicity and adverse event reporting (NCI-CTCAE Version 4.0 2009).

\section{Statistical analyses}

The subset of patients with major $B C R-A B L 1$ transcripts (i.e., b2a2 and/or b3a2) and $\leq 3$ months of prior imatinib treatment were included in the molecular analysis population. Patients with minor $B C R-A B L 1$ transcripts were excluded as the standard qRT-PCR methodology was not optimized for the detection of minor $B C R-A B L 1$ transcripts.

The landmark analysis included patients with major $B C R-A B L 1$ transcripts, with no prior imatinib exposure and evaluable qRT-PCR assessments at 3 months. Patients who already achieved the target response of MMR, $\mathrm{MR}^{4}$, and $\mathrm{MR}^{4.5}$ at 3 months were excluded from the landmark analysis of MMR, $\mathrm{MR}^{4}$, and $\mathrm{MR}^{4.5}$, respectively.

To calculate response rates "at" a designated time point, patients were considered responders only if an assessment at that time point showed achievement of response. Response rates "by" a designated time point were calculated as cumulative response rates, counting all patients with a response detected at or before the

Fig. 1 Patient disposition specified time point as responders. All response rates were calculated as raw proportions.

\section{Ethics}

This study was conducted in accordance with the International Conference on Harmonization Harmonized Tripartite Guidelines for Good Clinical Practice, the Declaration of Helsinki, and applicable local regulations. Informed consent was obtained from all individual participants included in the study. The protocol and informed consent forms were reviewed and approved by an institutional review board, independent ethics committee, or research ethics board before the study started at each participating institution. ENEST1st was registered in the EU Clinical Trials Registry (2009-017775-19) and ClinicalTrials.gov (NCT01061177).

\section{Results}

\section{Patient disposition and characteristics}

The study enrolled 1091 patients from 2010 to 2012 across 307 sites in 26 European countries, and 1089 patients who received $\geq 1$ dose of nilotinib $300 \mathrm{mg}$ twice daily were evaluated. Based on cytogenetic assessment, 983 patients were identified as $\mathrm{Ph}+$ and 30 patients were identified as $\mathrm{Ph}-$ at screening; 76 patients had unknown karyotype (Fig. 1). The 30 patients with $\mathrm{Ph}-$ status were positive for $B C R-A B L 1$ based on RT-PCR assessment. In the Ph- subset, no additional chromosomal aberrations were reported.

In the $\mathrm{Ph}+$ subgroup, 952 patients were evaluable for safety and efficacy, and in the $\mathrm{Ph}-/ B C R-A B L 1+$ subgroup,

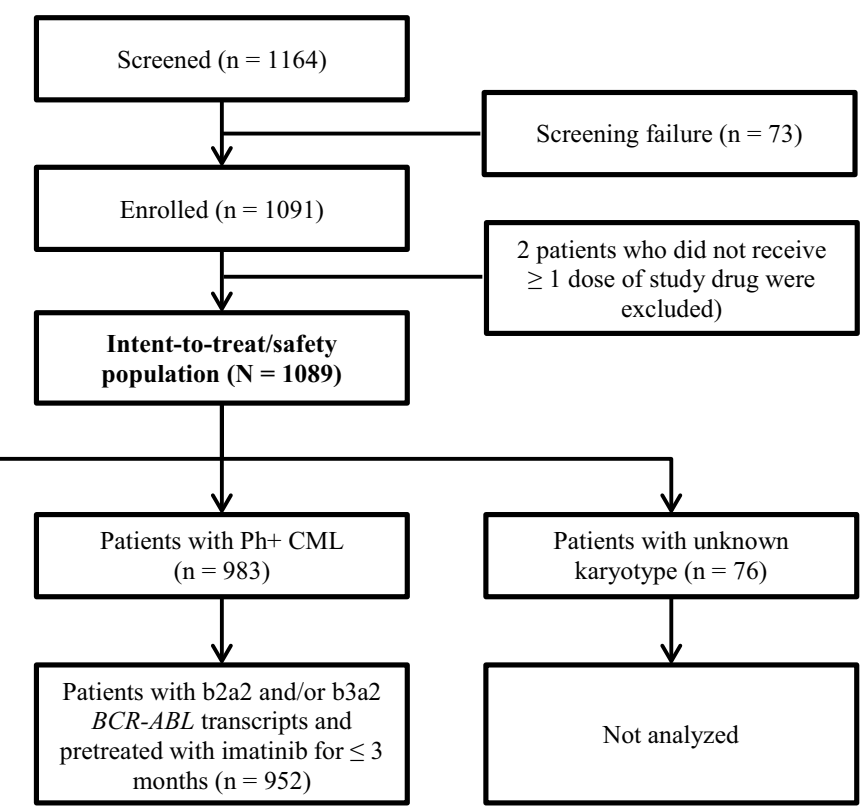


28 patients were evaluable for efficacy and all 30 patients were evaluable for safety (Fig. 1). Median age of patients with $\mathrm{Ph}-/ B C R-A B L 1+\mathrm{CML}$ was 51.5 years (range 21.0-75.0). In total, 26 patients (86.7\%) had low-risk EUTOS scores and 2 patients (6.7\%) had high-risk EUROS scores. Low, intermediate, and high Sokal risk scores were detected in 10 (33.3\%), 9 (30.0\%), and 7 patients (23.3\%), respectively. In the $\mathrm{Ph}+\mathrm{CML}$ subgroup, the median age was 53.0 years (range 18.0-91.0), EUTOS score was low in 806 patients $(82.0 \%)$ and high in 90 patients $(9.2 \%)$, and Sokal risk score was low, intermediate, and high in 342 (34.8\%), $366(37.2 \%)$, and 178 patients (18.1\%), respectively (Table 1).

\section{Molecular response}

In total, 28 patients met the criteria for molecular response analysis in the $\mathrm{Ph}-/ B C R-A B L 1+$ subgroup.
The proportion of patients who achieved the primary endpoint of $\mathrm{MR}^{4}$ at 18 months was similar in both subgroups, with $39.3 \%(n=11)$ in the $\mathrm{Ph}-/ B C R-A B L 1+$ subgroup and $38.1 \%(n=363)$ in the $\mathrm{Ph}+$ subgroup (Fig. 2). In the $\mathrm{Ph}-/ B C R-A B L 1+$ population, the $\mathrm{MR}^{4}$ rate was $28.6 \%$ at 12 months and $35.7 \%$ at 24 months. At 12 and 24 months, the respective rates of MMR were 53.6 and $50.0 \%$, and that of $\mathrm{MR}^{4.5}$ were 17.9 and $7.1 \%$ (Fig. 2). By 12 months, the cumulative rate of MMR was $75.0 \%$, $\mathrm{MR}^{4}$ was $42.9 \%$, and $\mathrm{MR}^{4.5}$ was $21.4 \%$. The cumulative rates of MMR, $\mathrm{MR}^{4}$, and $\mathrm{MR}^{4.5}$ by 24 months were 85.7, 60.7, and 50.0\%, respectively (Fig. 3). In the $\mathrm{Ph}+$ CML population, at 12 and 24 months, the rates of MMR were 55.7 and $61.4 \%$, respectively, $\mathrm{MR}^{4}$ were 30.7 and $40.4 \%$, respectively, and that of $\mathrm{MR}^{4.5}$ were 15.3 and $22.5 \%$, respectively (Fig. 2). The cumulative rates of $\mathrm{MMR}, \mathrm{MR}^{4}$, and $\mathrm{MR}^{4.5}$ were $68.3,36.7$, and $20.9 \%$ by 12 months, respectively, and $80.3,54.7$, and $38.3 \%$ by 24 months, respectively (Fig. 3).
Table 1 Baseline characteristics and demographics

\begin{tabular}{|c|c|c|}
\hline Parameter & $\begin{array}{l}\mathrm{Ph}-/ B C R-A B L 1+\mathrm{CML} \\
(n=30)\end{array}$ & $\mathrm{Ph}+\mathrm{CML}(n=983)$ \\
\hline Age, median (range), years & $51.5(21.0-75.0)$ & $53.0(18.0-91.0)$ \\
\hline Sex (Male/Female), $n(\%)$ & $17(56.7) / 13(43.3)$ & $581(59.1) / 402(40.9)$ \\
\hline \multicolumn{3}{|l|}{ Race, $n(\%)$} \\
\hline Caucasian & $30(100)$ & $941(95.7)$ \\
\hline \multicolumn{3}{|l|}{ Prior therapies ${ }^{\mathrm{a}, \mathrm{b}} n(\%)$} \\
\hline None & $5(16.7)$ & $301(30.6)$ \\
\hline Imatinib $\leq 1$ month & $2(6.7)$ & $59(6.0)$ \\
\hline Imatinib $>1-2$ months & $3(10.0)$ & $62(6.3)$ \\
\hline Imatinib $>2$ months & $10(33.3)$ & $35(3.6)$ \\
\hline Hydroxyurea & $10(33.3)$ & $524(53.3)$ \\
\hline \multicolumn{3}{|c|}{ Type of BCR-ABL transcripts, $n(\%)$} \\
\hline $\mathrm{b} 3 \mathrm{a} 2$ & $16(53.3)$ & $482(49.0)$ \\
\hline $\mathrm{b} 2 \mathrm{a} 2$ & $10(33.3)$ & $362(36.8)$ \\
\hline $\mathrm{b} 3 \mathrm{a} 2$ and $\mathrm{b} 2 \mathrm{a} 2$ & $3(10.0)$ & $111(11.3)$ \\
\hline Not assessed at baseline & $1(3.3)$ & $3(0.3)$ \\
\hline Sokal score, median (range) & $0.87(0.51-8.92)$ & $0.86(0.44-5.55)$ \\
\hline High risk, $n(\%)$ & $7(23.3)$ & $178(18.1)$ \\
\hline Intermediate risk, n (\%) & $9(30.0)$ & $366(37.2)$ \\
\hline Low risk, $n(\%)$ & $10(33.3)$ & $342(34.8)$ \\
\hline Missing, $n(\%)$ & $4(13.3)$ & $97(9.9)$ \\
\hline EUTOS score, median (range) & $0.39(0-0.94)$ & $0.34(0-3)$ \\
\hline High risk, $n(\%)$ & $2(6.7)$ & $90(9.2)$ \\
\hline Low risk, $n(\%)$ & $26(86.7)$ & $806(82.0)$ \\
\hline Missing, $n(\%)$ & $2(6.7)$ & $87(8.9)$ \\
\hline
\end{tabular}

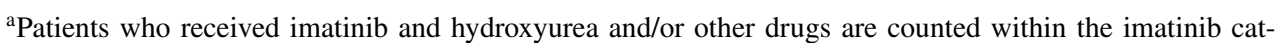
egories only. Patients who received hydroxyurea plus other drugs (not imatinib) are counted within the hydroxyurea category only

${ }^{\mathrm{b}}$ Two additional patients in the $\mathrm{Ph}+$ subgroup received therapies other than imatinib and/or hydroxyurea: one patient received cytarabine for 7 days, and other patient received capecitabine and oxaliplatin 
Fig. 2 Molecular responses during treatment at different time points in $\mathrm{Ph}-/ B C R$ $A B L 1+\mathrm{CML}(n=28)(\mathbf{a})$ and $\mathrm{Ph}+\mathrm{CML}(n=952)(\mathbf{b}) . M M R$ major molecular response $\left(\mathrm{BCR}-\mathrm{ABL} 1^{\mathrm{IS}} \leq 0.1 \%\right), M R$ molecular response, $M R^{4} \mathrm{MR}$ with 4-log reduction in BCRABL transcript (BCR-ABL1 ${ }^{\text {IS }}$ $\leq 0.01 \%), M R^{4.5} \mathrm{MR}$ with 4.5-log reduction in $\mathrm{BCR}-\mathrm{ABL}$ transcript $\left(\mathrm{BCR}-\mathrm{ABL} 1^{\mathrm{IS}} \leq\right.$ $0.0032 \%)$
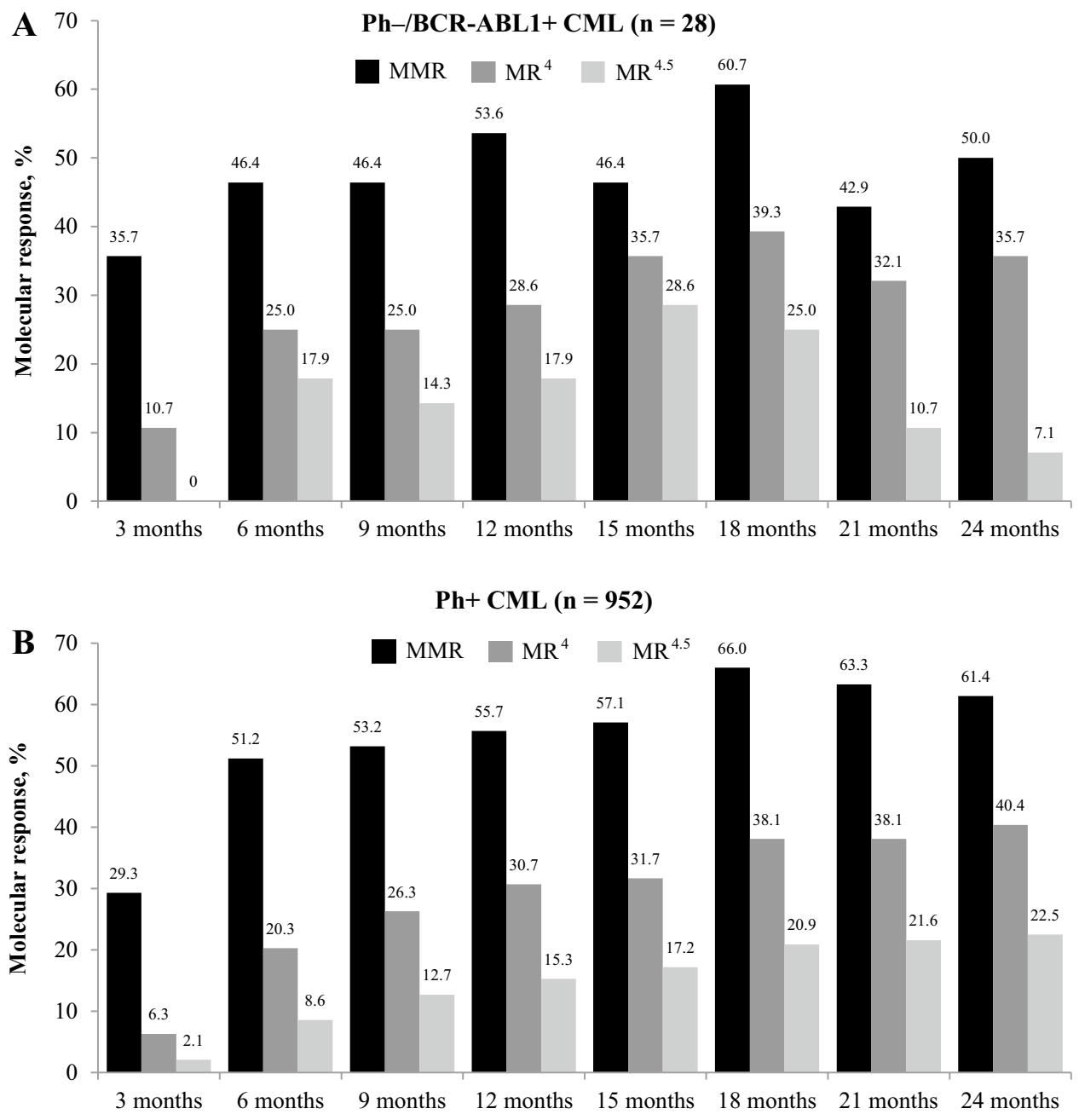

Ph+ CML $(n=952)$

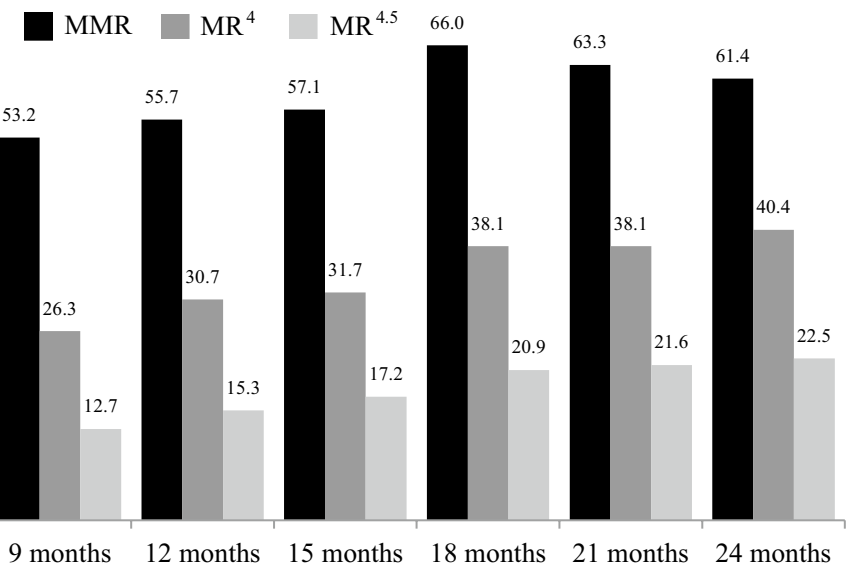

\section{Landmark analysis}

Of the 14 patients with $\mathrm{Ph}-/ B C R-A B L 1+\mathrm{CML}, 12$ $(85.7 \%)$ had BCR-ABL1 ${ }^{\mathrm{IS}} \leq 1 \%$, and 1 had BCR-ABL1 $1^{\mathrm{IS}}$ $>1$ to $\leq 10 \%$ at 3 months. In patients with BCR-ABL $1^{\text {IS }}$ $\leq 1 \%$ at 3 months, the cumulative incidence of MMR was $77.8 \%$ (7/9 patients), $\mathrm{MR}^{4}$ was $58.3 \%$ (7/12 patients), and $\mathrm{MR}^{4.5}$ was $41.7 \%$ (5/12 patients) by 24 months.

In the $\mathrm{Ph}+\mathrm{CML}$ subgroup, the cumulative rates of MMR by 24 months were $88 \%$ (300/338 patients), $57.4 \%$ (78/136 patients), and $36.4 \%$ (8/22 patients) in patients with BCR-ABL $1^{\mathrm{IS}} \leq 1 \%,>1$ to $\leq 10 \%$, and $>10 \%$ at 3 months, respectively. The cumulative rates of $\mathrm{MR}^{4}$ and $\mathrm{MR}^{4.5}$ by 24 months were $64.8 \%$ (333/514 patients) and 46.1\% (251/545 patients), respectively, in patients with BCR-ABL1 ${ }^{\mathrm{IS}}>0 \%$ to $\leq 1 \%$ at 3 months, and $24.3 \%$ (33/136 patients) and $14 \%$ (19/136 patients), respectively, in patients with BCR$\mathrm{ABL}^{\mathrm{IS}}>1$ to $\leq 10 \%$ at 3 months.

\section{Safety}

The most frequently reported $(\geq 10 \%)$ nonhematological AEs (all grades) included rash (20.0\%), pruritus (16.7\%), nasopharyngitis (13.3\%), diarrhea $(10.0 \%)$, fatigue $(10.0 \%)$, arthralgia $(10.0 \%)$, headache $(10.0 \%)$, and hypertension $(10.0 \%)$ in the $\mathrm{Ph}-/ B C R-A B L 1+$ subgroup, and rash $(22.0 \%)$, pruritus $(16.7 \%)$, headache $(15.8 \%)$, fatigue $(14.2 \%)$, nausea $(11.4 \%)$, alopecia $(11.0 \%)$, and nasopharyngitis $(10.4 \%)$ in the $\mathrm{Ph}+$ subgroup (Table 2 ).

The most common $(\geq 10 \%)$ hematological/biochemical laboratory abnormalities (all grades) were hypophosphatemia (23.3\%), alanine aminotransferase increase (ALT, 13.3\%), bilirubin increase (13.3\%), aspartate aminotransferase increase (AST; 10.0\%), lipase increase $(10.0 \%)$, and anemia $(10.0 \%)$ in the $\mathrm{Ph}-/ B C R$ $A B L 1+$ subgroup, and thrombocytopenia $(10.2 \%)$ in the $\mathrm{Ph}+$ subgroup (Table 2). 
Fig. 3 Cumulative rate of $\operatorname{MMR}(\mathbf{a}), \mathrm{MR}^{4}$ (b), and $\mathrm{MR}^{4.5}$ (c) in $\mathrm{Ph}-/ B C R-A B L 1+$ and $\mathrm{Ph}+$ subgroups by 24 months. $M M R$ major molecular response ${\left.\text { (BCR-ABL } 1^{\mathrm{IS}} \leq 0.1 \%\right), M R}$ molecular response, $M R^{4} \mathrm{MR}$ with 4- $\log$ reduction in BCRABL transcript (BCR-ABL1 ${ }^{\text {IS }}$ $\leq 0.01 \%), M R^{4.5} \mathrm{MR}$ with 4.5-log reduction in BCRABL transcript (BCR-ABL1 ${ }^{\mathrm{IS}}$ $\leq 0.0032 \%$ )
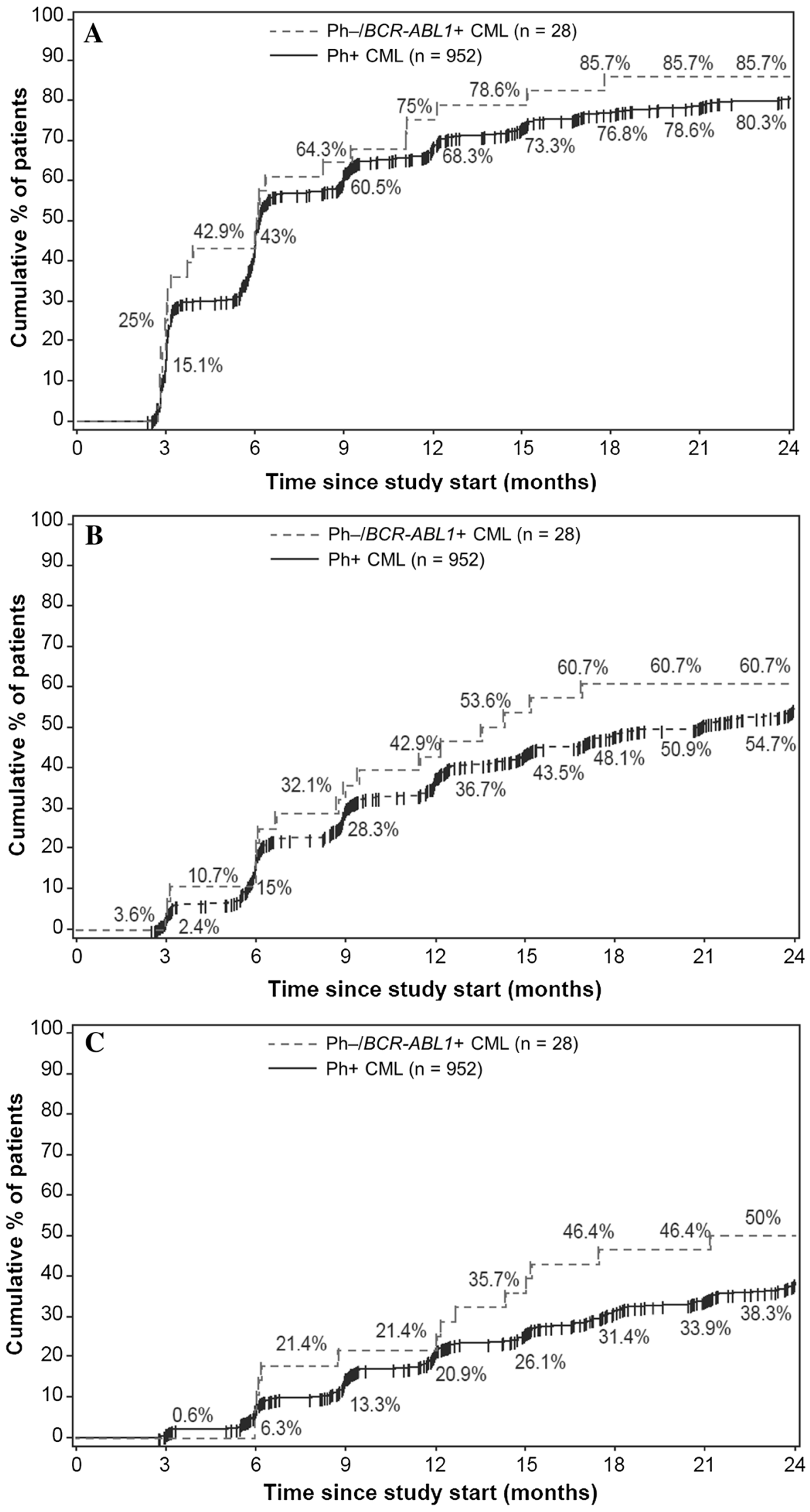
Table 2 Adverse events and laboratory abnormalities occurring in $\geq 10 \%$ of patients at any grade or $\geq 1 \%$ of patients at grade $3 / 4$ in the $\mathrm{Ph}-/ B C R$ $A B L 1+\mathrm{CML}$ or $\mathrm{Ph}+\mathrm{CML}$ subgroups

\begin{tabular}{|c|c|c|c|c|c|c|}
\hline \multirow[t]{2}{*}{ Patients, $n(\%)^{\mathrm{a}}$} & \multicolumn{3}{|c|}{$\mathrm{Ph}-/ B C R-A B L 1+\mathrm{CML} n=30$} & \multicolumn{3}{|c|}{$\mathrm{Ph}+\mathrm{CML} n=952$} \\
\hline & All grades & Grade 3 & Grade 4 & All grades & Grade 3 & Grade 4 \\
\hline \multicolumn{7}{|l|}{ Non-hematological events } \\
\hline Rash & $6(20.0)$ & 0 & 0 & $209(22.0)$ & $4(0.4)$ & 0 \\
\hline Pruritus & $5(16.7)$ & $1(3.3)$ & 0 & $159(16.7)$ & $2(0.2)$ & 0 \\
\hline Nasopharyngitis & $4(13.3)$ & 0 & 0 & $99(10.4)$ & 0 & 0 \\
\hline Diarrhea & $3(10.0)$ & 0 & 0 & $86(9.0)$ & $1(0.1)$ & 0 \\
\hline Fatigue & $3(10.0)$ & 0 & 0 & $135(14.2)$ & $7(0.7)$ & 0 \\
\hline Arthralgia & $3(10.0)$ & 0 & 0 & $87(9.1)$ & $2(0.2)$ & 0 \\
\hline Headache & $3(10.0)$ & 0 & 0 & $150(15.8)$ & $7(0.7)$ & 0 \\
\hline Hypertension & $3(10.0)$ & 0 & 0 & $56(5.9)$ & $11(1.2)$ & 0 \\
\hline Dry skin & $2(6.7)$ & 0 & 0 & $88(9.2)$ & 0 & 0 \\
\hline Nausea & $2(6.7)$ & 0 & 0 & $109(11.4)$ & $5(0.5)$ & 0 \\
\hline Back pain & $2(6.7)$ & 0 & 0 & $69(7.2)$ & $4(0.4)$ & 0 \\
\hline Myalgia & $2(6.7)$ & 0 & 0 & $87(9.1)$ & $2(0.2)$ & 0 \\
\hline Urticaria & $1(3.3)$ & $1(3.3)$ & 0 & $11(1.2)$ & $1(0.1)$ & 0 \\
\hline Drug hypersensitivity & $1(3.3)$ & $1(3.3)$ & 0 & $1(0.1)$ & 0 & 0 \\
\hline Dermal cyst & $1(3.3)$ & $1(3.3)$ & 0 & $3(0.3)$ & 0 & 0 \\
\hline Alopecia & $1(3.3)$ & 0 & 0 & $105(11.0)$ & $1(0.1)$ & 0 \\
\hline \multicolumn{7}{|l|}{ Hematological laboratory events } \\
\hline Anemia & $3(10.0)$ & 0 & $3(10.0)$ & 0 & 0 & $62(6.5)$ \\
\hline Thrombocytopenia & $1(3.3)$ & 0 & $1(3.3)$ & 0 & $1(3.3)$ & $97(10.2)$ \\
\hline Neutropenia & 0 & 0 & 0 & 0 & 0 & $41(4.3)$ \\
\hline \multicolumn{7}{|l|}{ Biochemical laboratory events } \\
\hline Hypophosphatemia & $7(23.3)$ & $2(6.7)$ & $7(23.3)$ & $2(6.7)$ & 0 & $65(6.8)$ \\
\hline Alanine aminotransferase increase & $4(13.3)$ & $1(3.3)$ & $4(13.3)$ & $1(3.3)$ & 0 & $79(8.3)$ \\
\hline Bilirubin increase & $4(13.3)$ & 0 & $4(13.3)$ & 0 & 0 & $70(7.4)$ \\
\hline Lipase increase & $3(10.0)$ & 0 & $3(10.0)$ & 0 & 0 & $71(7.5)$ \\
\hline Aspartate aminotransferase increase & $3(10.0)$ & 0 & $3(10.0)$ & 0 & 0 & $45(4.7)$ \\
\hline
\end{tabular}

${ }^{a}$ Excludes events that started $>28$ days after last dose of study drug or month 24
In patients with $\mathrm{Ph}-/ B C R-A B L 1+\mathrm{CML}$, two patients (7.1\%) experienced grade 3 hypophosphatemia and one patient each (3.6\%) experienced dermal cyst, pruritus, urticaria, and ALT increase of grade 3 severity; three patients experienced cardiovascular events, including four grade 3 events. Grade 4 anemia occurred in 1 patient (Table 2).

In the $\mathrm{Ph}+$ subgroup, thrombocytopenia, lipase increase, neutropenia and hypophosphatemia, anemia, ALT increase, and bilirubin increase of grade 3 severity were experienced by $37(3.9 \%), 30(3.2 \%), 20(2.1 \%), 19(2 \%), 17(1.8 \%)$, $14(1.5 \%)$, and $13(1.4 \%)$ patients, respectively. Grade 4 thrombocytopenia, neutropenia, and lipase increase were reported in $22(2.3 \%), 8(0.8 \%)$, and $7(0.7 \%)$ patients, respectively (Table 2 ).

\section{Discussion}

The development of BCR-ABL TKIs has revolutionized the therapeutic landscape of CML-CP. However, these TKIs have only been approved for the treatment of patients with Ph+ CML (Baccarani et al. 2013; Bisen and Claxton 2013; NCCN 2016). Sufficient literature is available on the effect of TKIs on patients with $\mathrm{Ph}+/ B C R-A B L 1+\mathrm{CML}$; however, the effect of TKIs in patients with $\mathrm{Ph}-/ B C R-A B L 1+\mathrm{CML}$ has not been widely explored. This report, to the best of our knowledge, is the first of its kind to present data on the effect of nilotinib in patients with $\mathrm{Ph}-/ B C R-A B L 1+\mathrm{CML}$.

In a previous study, the efficacy of interferon-alpha was evaluated in patients with $\mathrm{Ph}-/ B C R-A B L 1+\mathrm{CML}$ in early $\mathrm{CP}$. Of the 14 patients who received interferon-alpha, 12 achieved complete hematologic remission, and the median survival duration was 60 months (range 3->90 months). Patients with $\mathrm{Ph}+\mathrm{CML}$ and $\mathrm{Ph}-/ B C R-A B L 1+\mathrm{CML}$ were found to have similar characteristics and outcomes (Cortes et al. 1995).

In the ENEST1st study, among 1052 patients evaluable, the cumulative rates of MMR, $\mathrm{MR}^{4}$, and $\mathrm{MR}^{4.5}$ were $80.4 \%$, 55.2\%, and $38.6 \%$, respectively, by 24 months (Hochhaus et al. 2016a). At 24 months, the estimated 
overall survival rate was $98.9 \%$ (95\% CI, 98.0-99.4\%), with 13 on study deaths reported, and the estimated rate of freedom from progression to accelerated phase/blast crisis (AP/BC) was $99.4 \%$ (95\% CI, 98.7-99.7\%). None of the six patients who progressed to AP/BC on treatment died during study (Hochhaus et al. 2016a). Results from this study confirm that patients on nilotinib can achieve deep molecular responses, as previously seen in the ENESTnd study (Hochhaus et al. 2016b).

In the current sub-analysis of the ENEST1st trial, the primary endpoint of $\mathrm{MR}^{4}$ at 18 months was similar between $\mathrm{Ph}+(39.3 \%)$ and $\mathrm{Ph}-/ B C R-A B L 1+(38.1 \%)$ populations. The safety profile of nilotinib was also similar between the two populations, with the most frequently reported AEs being hypophosphatemia (23.3\%), rash $(20.0 \%)$, and pruritus $(16.7 \%)$ in the $\mathrm{Ph}-/ B C R-A B L 1+$ population, and rash $(22.0 \%)$, pruritus $(16.7 \%)$, and headache $(15.8 \%)$ in the $\mathrm{Ph}+$ population. The overall safety results from this study were consistent with the safety profile of nilotinib and similar to that observed in the ENESTnd study (Hochhaus et al. 2016b; Kantarjian et al. 2011; Larson et al. 2012; Saglio et al. 2010; Steegmann et al. 2016).

Patients with $\mathrm{Ph}-/ B C R-A B L 1+\mathrm{CML}$ and those with unconfirmed $\mathrm{Ph}$ status at screening and no $\mathrm{Ph}+$ metaphases at later time points were not eligible for cytogenetic response analysis. Of the 983 patients evaluable, complete cytogenetic response rate was $67.3 \%(n=662 ; 95 \% \mathrm{CI}$, $64.4-70.3 \%)$ by 6 months and $82.5 \%(n=811 ; 95 \% \mathrm{CI}$, $80.1-84.9 \%$ ) by 12 months (Hochhaus et al. 2016a). In the overall population in the ENEST1st study, $97 \%$ of the patients achieved $B C R-A B L I^{\mathrm{IS}} \leq 10 \%$ at 3 months (Hochhaus et al. 2016a), a molecular target which is recommended for the achievement of better long-term outcomes (Baccarani et al. 2013; NCCN 2016), as seen in prior studies (Hanfstein et al. 2012; Hughes et al. 2014; Jabbour et al. 2014; Marin et al. 2012). Based on the landmark analysis, greater proportion of patients with $B C R-A B L I^{\mathrm{IS}} \leq 1 \%$ at 3 months vs $B C R-A B L 1^{\mathrm{IS}}>1 \%$ at 3 months achieved $\mathrm{MR}^{4}$ (65.0 vs $24.1 \%$ ) and $\mathrm{MR}^{4.5}$ (45.8 vs $14.5 \%$ ) by 24 months (Hochhaus et al. 2016a). However, this conclusion cannot be drawn in $\mathrm{Ph}-/ B C R-A B L 1+$ patients due to lower patient count. In total, 12 of the 14 patients evaluable had $B C R$ $A B L I^{\mathrm{IS}} \leq 1 \%$ at 3 months, and only one patient had $B C R$ $A B L 1^{\mathrm{IS}}>1 \%$ at 3 months; by 24 months, 58 and $41.7 \%$ of the patients with $B C R-A B L I^{\mathrm{IS}} \leq 1 \%$ at 3 months achieved $\mathrm{MR}^{4}$ and $\mathrm{MR}^{4.5}$, respectively.

The study was not designed to compare the two patient populations; also due to huge disparity between the numbers in each group, any meaningful comparisons cannot be drawn.

In conclusion, baseline characteristics, risk scores, and MR rates were found to be similar between the $\mathrm{Ph}-/ B C R$ $A B L 1+$ and $\mathrm{Ph}+$ subgroups, and nilotinib is active in this previously unexplored population. Adverse events observed in $\mathrm{Ph}-/ B C R-A B L 1+\mathrm{CML}$ patients were also found to be similar to the ones observed in the $\mathrm{Ph}+\mathrm{CML}$ patients. In the background of similar molecular response and safety profiles seen in patients with $\mathrm{Ph}-/ B C R-A B L 1+\mathrm{CML}$ when compared with the $\mathrm{Ph}+\mathrm{CML}$ population, this rare population subgroup benefits from nilotinib treatment in the same way as $\mathrm{Ph}+$ patients.

Acknowledgements We thank all physicians, study coordinators and documentation assistants for their active participation and cooperation. In addition to the authors of this report, members of the Scientific Study Management Committee included Philippe Rousselot, MD and David Marin, MD and members of the data management committee included Nelson Spector, MD, PhD and Armand Keating, MD, FRCP. We also thank Vijay Kadasi, MSc, Novartis Healthcare Pvt Ltd for medical editorial assistance with this manuscript.

\section{Compliance with ethical standards}

Conflict of interest Hochhaus A Research funding-Novartis, Pfizer, Ariad, and BMS. Mahon FX Nothing to disclose. Le Coutre P Nothing to disclose. Petrov L Nothing to disclose. Jeroen JWM Janssen Research support-Novartis and BMS; Advisory board-Novartis, BMS, Pfizer, and Ariad/Incyte; Speaker's honoraria-Ariad/Incyte and Pfizer. Nicholas C.P. Cross Research funding, Advisory board and speaker's fee-Novartis; Delphine Rea Honoraria-Novartis, BMS, Pfizer, and Incyte. Castagnetti F Consultancy and honorariaNovartis, BMS, Incyte, and Pfizer. Hellmann A Nothing to disclose. Rosti $G$ Nothing to disclose. Gattermann $N$ Speaker's honoraria and travel support-Novartis. Coronel MLP Nothing to disclose. Gutierrez MAE Nothing to disclose. Gutierrez JVV Honoraria and Research funding-Novartis, BMS, Pfizer, and Ariad. Vincenzi B Employees of Novartis. Dezzani L Employees of Novartis. Giles FJ ConsultancyNovartis.

Funding The study was sponsored by Novartis Pharmaceuticals.

Open Access This article is distributed under the terms of the Creative Commons Attribution 4.0 International License (http:// creativecommons.org/licenses/by/4.0/), which permits unrestricted use, distribution, and reproduction in any medium, provided you give appropriate credit to the original author(s) and the source, provide a link to the Creative Commons license, and indicate if changes were made.

\section{References}

Baccarani M et al (2013) European LeukemiaNet recommendations for the management of chronic myeloid leukemia: 2013. Blood 122:872-884. doi:10.1182/blood-2013-05-501569

Bartram CR (1985) bcr Rearrangement without juxtaposition of c-abl in chronic myelocytic leukemia. J Exp Med 162:2175-2179

Bartram CR et al (1983) Translocation of c-ab1 oncogene correlates with the presence of a Philadelphia chromosome in chronic myelocytic leukaemia. Nature 306:277-280

Bisen A, Claxton DF (2013) Tyrosine kinase targeted treatment of chronic myelogenous leukemia and other myeloproliferative neoplasms. Adv Exp Med Biol 779:179-196. doi:10.1007/978-1-4614-6176-0_8 
Cortes JE, Talpaz M, Beran M, O’Brien SM, Rios MB, Stass S, Kantarjian HM (1995) Philadelphia chromosome-negative chronic myelogenous leukemia with rearrangement of the breakpoint cluster region. Long-term follow-up results. Cancer 75:464-470

Cross NC, Melo JV, Feng L, Goldman JM (1994) An optimized multiplex polymerase chain reaction (PCR) for detection of BCR$\mathrm{ABL}$ fusion mRNAs in haematological disorders. Leukemia 8:186-189

Cross NC, White HE, Müller MC, Saglio G, Hochhaus A (2012) Standardized definitions of molecular response in chronic myeloid leukemia. Leukemia 26:2172-2175. doi:10.1038/ leu.2012.104

de Klein A et al (1982) A cellular oncogene is translocated to the Philadelphia chromosome in chronic myelocytic leukaemia. Nature 300:765-767

Fitzgerald PH, Morris CM (1991) Complex chromosomal translocations in the Philadelphia chromosome leukemias. Serial translocations or a concerted genomic rearrangement? Cancer Genet Cytogenet 57:143-151

Hanfstein B et al (2012) Early molecular and cytogenetic response is predictive for long-term progression-free and overall survival in chronic myeloid leukemia (CML). Leukemia 26:2096-2102. doi:10.1038/leu.2012.85

Heim S, Billstrom R, Kristoffersson U, Mandahl N, Strombeck B, Mitelman F (1985) Variant Ph translocations in chronic myeloid leukemia. Cancer Genet Cytogenet 18:215-227

Hochhaus A et al (2016a) Frontline nilotinib in patients with chronic myeloid leukemia in chronic phase: results from the European ENEST1st study. Leukemia 30:57-64. doi:10.1038/leu.2015.270

Hochhaus A et al (2016b) Long-term benefits and risks of frontline nilotinib vs imatinib for chronic myeloid leukemia in chronic phase: 5-year update of the randomized ENESTnd trial. Leukemia 30:1044-1054. doi:10.1038/leu.2016.5

Hughes T, Branford S (2006) Molecular monitoring of BCR-ABL as a guide to clinical management in chronic myeloid leukaemia. Blood Rev 20:29-41. doi:10.1016/j.blre.2005.01.008

Hughes TP et al (2014) Early molecular response predicts outcomes in patients with chronic myeloid leukemia in chronic phase treated with frontline nilotinib or imatinib. Blood 123:13531360. doi:10.1182/blood-2013-06-510396

Jabbour E et al (2014) Early response with dasatinib or imatinib in chronic myeloid leukemia: 3-year follow-up from a randomized phase 3 trial (DASISION). Blood 123:494-500. doi:10.1182/ blood-2013-06-511592

Kantarjian HM et al (2011) Nilotinib versus imatinib for the treatment of patients with newly diagnosed chronic phase, Philadelphia chromosome-positive, chronic myeloid leukaemia: 24-month minimum follow-up of the phase 3 randomised ENESTnd trial. Lancet Oncol 12:841-851. doi:10.1016/s1470-2045(11)70201-7

La Starza R et al (2002) Complex variant Philadelphia translocations involving the short arm of chromosome 6 in chronic myeloid leukemia. Haematologica 87:143-147

Larson RA et al (2012) Nilotinib vs imatinib in patients with newly diagnosed Philadelphia chromosome-positive chronic myeloid leukemia in chronic phase: ENESTnd 3-year follow-up. Leukemia 26:2197-2203. doi:10.1038/leu.2012.134

Marin D et al (2012) Assessment of BCR-ABL1 transcript levels at 3 months is the only requirement for predicting outcome for patients with chronic myeloid leukemia treated with tyrosine kinase inhibitors. J Clin Oncol 30:232-238. doi:10.1200/ jco.2011.38.6565

Martiat P, Michaux JL, Rodhain J (1991) Philadelphia-negative ( $\mathrm{Ph}-)$ chronic myeloid leukemia (CML): comparison with $\mathrm{Ph}+\mathrm{CML}$ and chronic myelomonocytic leukemia. The Groupe Francais de Cytogenetique Hematologique. Blood 78:205-211

Müller MC et al (2008) Harmonization of BCR-ABL mRNA quantification using a uniform multifunctional control plasmid in 37 international laboratories. Leukemia 22:96-102. doi:10.1038/ sj.leu. 2404983

NCCN (2016) National Comprehensive Cancer Network (NCCN) clinical practice guidelines in oncology: chronic Myelogenous Leukemia, v1., National Comprehensive Cancer Network, Fort Washington

NCI-CTCAE (Version 4.0 2009) National Cancer Institute (NCI) Common Terminology Criteria for Adverse Events (CTCAE), version 4.0. National Cancer Institute: Bethesda

Nishigaki H, Misawa S, Inazawa J, Abe T (1992) Absence in $\mathrm{Ph}$ negative. $\mathrm{M}-\mathrm{BCR}$ rearrangement-positive chronic myelogenous leukemia of linkage between $5^{\prime} \mathrm{ABL} 3^{\prime} \mathrm{M}-\mathrm{BCR}$ sequences in Philadelphia translocation. Leukemia 6:385-392

Rowley JD (1973) Letter: a new consistent chromosomal abnormality in chronic myelogenous leukaemia identified by quinacrine fluorescence and Giemsa staining. Nature 243:290-293

Saglio G et al (2010) Nilotinib versus imatinib for newly diagnosed chronic myeloid leukemia. N Engl J Med 362:2251-2259. doi:10.1056/NEJMoa0912614

Seong D et al (1999) Analysis of Philadelphia chromosome-negative BCR-ABL-positive chronic myelogenous leukemia by hypermetaphase fluorescence in situ hybridization. Ann Oncol 10:955-959

Sessarego M, Fugazza G, Bruzzone R, Ballestrero A, Miglino M, Bacigalupo A (2000) Complex chromosome rearrangements may locate the bcr/abl fusion gene sites other than 22q11. Haematologica 85:35-39

Shtivelman E et al (1987) bcr-abl RNA in patients with chronic myelogenous leukemia. Blood 69:971-973

Steegmann JL et al (2016) European LeukemiaNet recommendations for the management and avoidance of adverse events of treatment in chronic myeloid leukaemia. Leukemia 30:1648-1671. doi:10.1038/leu.2016.104

Tasigna (2015) Tasigna [package insert]. Novartis Pharmaceuticals Corporation, East Hanover

Todoric-Zivanovic B et al (2006) A Ph-negative chronic myeloid leukemia with a complex BCR/ABL rearrangement and a $\mathrm{t}(6 ; 9)(\mathrm{p} 21 ; \mathrm{q} 34.1)$. Cancer Genet Cytogenet 166:180-185. doi:10.1016/j.cancergencyto.2005.11.008 